Bangladesh Journal of Bioethics 2015; 6(1):6-10

\title{
Children as Research Subjects: The Ethical Issues
}

\author{
Dr. Nahid Ferdousi \\ Associate Professor of Law \\ Bangladesh Open University \\ Email: nahid329@yahoo.com
}

\begin{abstract}
From the very beginning of civilization, children are made the subject matter of many social and clinical researches. Due to the vulnerabilities of physical frailty and mental immaturity, children's interests and rights need to be protected from the risks associated with any kind of research. Recently, there has been increased global concern towards the involvement of children in research for the protection of their rights by the ethical research practice. It emphasizes upon the ongoing nature of ethical considerations that ethical issues need to be considered throughout the research process and even the post research ethical issues are equally significant. The study explores some of the major ethical issues that arise in research involving children during and after the research in terms of the best interests of the children.
\end{abstract}

Keywords: research; children; best interest; ethics; practice

Introduction: Research stands for the systematic study of different social objects and phenomena which include human beings as they are the integral part of the society. There are so many vulnerable groups who have been being used as subjects of different kinds of research and the ethics of the research is required to uphold their rights, especially for the children. The basic principles of ethics ensure the principles of justice, mutual respect and the avoidance of doing harm to children subject to any research. As human beings, children are the beneficiaries of rights as articulated under a number of international human rights instruments for example, the International Covenant on Civil and Political Rights (ICCPR) 1966 and United Nations Convention on the Rights of the Child (UNCRC) 1989. These principles require that researchers attend to the relational as well as the procedural dimensions of research ${ }^{1}$.

Each state has a set of ethical rules as well as several international organizations and researchers have played a critically important role in developing ethical guidance for research involving children. The researchers must consider the potential negative impacts of research for the children's lives, sense of identity and belongingness and the course of data collection, information gathering, interpretation and analysis of the collected data. In fact, the principle of beneficence refers to the actions that promote the well-being of children. Rosie Flewitt (2005) argued that researchers have a responsibility towards the participants of all ages not only to establish a robust and negotiated ethical framework for their research, but also to ensure that these ethical principles are applied throughout the stages of the research process. ${ }^{2}$

From a historical perspective, research involving children have undoubtedly contribution to the generalization of knowledge and the construction of a body of information about the minds and behaviors of children. There are numerous ways of doing so. However, it is necessary for the researcher to recognize the reality of studying the children participants. Research governance has expanded and a burgeoning literature is emerging that describes the processes, practices and difficulties that arise in social research in both developed and developing countries. ${ }^{3}$ In Europe and the USA, medical research has developed standards over several decades and the social researchers 
also agree to observe high ethical standards. In fact, children should not be placed at a disadvantage by being enrolled in a clinical trial, either through exposure to excessive risks or by failing to get necessary health care ${ }^{4}$.

In practice, most of the research, children may be at the ethical questions that arise are about the best interests, the risks, the justification of a research for subjects along with the rights of the children and the authority of parents to give permission, the assent and consent which are related to children in research. Similarly, the way in which these ethical issues are tackled in practice can be quite different from each other. Often the way of conducting such researches could ignore, although most times unintentionally, the children's rights. Consequently, the children are presented as the silent victims of a tragedy, or are included in clinical research without their consent; whereas their human rights and their right to be protected are being jeopardized ${ }^{5}$.

Historical Background: The historical origin of the ethical principles for research with children arose from the Nuremberg Trials, which took place after the Second World War and the Nuremberg Code of 1947, which emerged first of these. The Nuremberg Code 1947 applied particularly to experimental research, although it had wider relevance to the key ethical principles in terms of voluntary consent, freedom to consent and avoidance of unnecessary pain or harm. The Code sets out statements of certain moral, ethical and legal principles relating to the research involving human subjects. Initially, these ethical guidelines were primarily concerned with medical research. However, they were subsequently used as a basis for guidelines for social research.

Thereafter, the emergence of the Declaration of Helsinki in 1964 which amended in 1989 and 1996 now includes an examination of the issue of children as research subjects in relation to informed consent in clinical research. The principles for conducting research contained in the Declaration of Helsinki apply to all human subjects, adults and children. The declaration indicated that adequate information must be provided to the research participants as well as participation in the research must be freely volunteered with the understanding that the participant can withdraw at any time. In addition, informed consent should be obtained, preferably in writing by the principles. There is one section, which refers specifically to research with children and states: "when the subject is a minor, permission from the responsible relative replaces that of the participant in accordance with national legislation. Whenever the minor child is in fact able to give consent, the minor's consent must be obtained in addition to the consent of the minor's legal guardian. ${ }^{6}$ However, there are different guidelines about the ethics of research with children, related to different disciplinary perspectives. ${ }^{7}$

Methods: This is a review article done during the participation in training course on Ethical and Regulatory Aspects of Clinical Research, Organized by Bangladesh Bioethics Society in collaboration with Department of Bioethics, NIH, USA through video conferencing on 01 October, 2014 to 12 November, 2014. The search was confined to Google search and published articles.

Discussion: Research in children is recognized as a moral duty based on several ethical principles. ${ }^{8}$ These $^{-}$ principles are universal, though there are of course many subtleties and diversities, and the contingent aspects of how principles are understood, interpreted and practiced can vary from place to place. In child research, the ethical questions about how to conduct research are deeply connected with the content of social or clinical theory. ${ }^{9}$ However, many factors have to be taken into consideration so that the general research conditions are improved and not to the benefit of any particular party. ${ }^{10}$ 
Ethical Challenges during Research: The general purpose of research that involves children is to obtain and produce scientific information about them. In this backdrop, the researchers should focus on the issues arising during research and take all reasonable precautions to ensure children will not be harmed or adversely affected by participating in the research. ${ }^{11}$ Similarly, researchers have to ensure that the children participating do so at their own volition and that the rights of the child are fully respected in the research process. The researcher is also obligated at all times to use the least stressful research procedure whenever possible. But the benefits of conducting such research must be balanced with ethical concerns. ${ }^{12}$ The research in children has based its ethical guidance around some of the following principles:

1. Informed consent: In every case informed consent must be obtained from the child's legal representative and the child's assent should be obtained through the provision of age-appropriate information. The application of general principles indicates that, where children have "sufficient understanding and intelligence to understand what is proposed", it is they and not their parents whose consent is required by law ${ }^{13}$.

The Nuremberg Code 1949 appears to introduce the concept of consent for the participation of children in research. According to the Declaration of Helsinki, even though a child may not be legally competent to give consent, researchers should gain informed consent. This means that parental consent is not enough and that both the parents and child should be informed about the implications of the research. Parental and/or guardian's (informed) consent is required for a child (a person below the age of 18) to participate in research. It is essential that the child has the full information about the research in order to give their 'informed consent' to take part, and that consent is 'freely volunteered' ${ }^{14}$.

2. Assent and children's indications of rejection: Information presented to the child and parent, should explain: what will happen; what is being asked of the child; that the child can agree - or disagree to take part - without adverse consequences; and may withdraw at any time; and be given in clear language at a level that the child can understand, using visual aids if necessary. ${ }^{15}$ If children are not fully informed of the research topic, informed consent is automatically denied even if the children are able to decide about participation, since informed consent exists only when one is fully informed ${ }^{16}$.

3. Child protection and well-being: Research involving children is important for the benefit of all children and should be supported, encouraged and conducted in an ethical manner. In the course of research, information comes to the researchers' attention that may jeopardize the child's well-being. The researcher has a responsibility to discuss the information with the parents or guardians and with those experts in the field in order that they may arrange the necessary assistance for the child. Thus, if at any time during the research process there is an indication that a child's safety or well-being is being negatively affected; the research must be kept suspended until the issue has been addressed. If the child appears to be negatively affected by the research, the parent or guardian must be informed and the child and family must be offered with appropriate support. Besides, extra time and support should be given for the children. Similarly, dissemination of findings will need to be informed by an understanding of the specific communication needs of the children and their families ${ }^{17}$.

4. Minimizing the risk of harm: Ethical guidance and practices aim to minimize possible exploitation and ensure that the rights and welfare of children in research. Accordingly, a key ethical consideration in research involving children is 
the level of risk to which children may be exposed. Risk refers to the potential harm (physical, psychological or social) that may arise from the research. The researcher should pose more identifiable risks of harm. Similarly, researchers should not use those types of research procedure that may harm the child either physically or psychologically ${ }^{18}$.

Ethics after Research: Ethics after the research in children of equal importance like the ethics upheld throughout. The researcher has to ensure the ethical processing of data, the way this data will be stored and made available to others. Personal data are usually protected by data protection laws, but there could be situations where a parent, who has provided consent, requires information about the research results, while the child participating in the research has been assured that her/ his answers will not be revealed. The topic of confidentiality is very problematic both for achieving the previously mentioned balance and protecting children participants from disclosure. One way of getting over this challenge is to ask for permission of the child subject to disclose information about the research afterwards although what the child understands can be very different ${ }^{19}$.

Hence, confidentiality is very important since the disclosure of information can put the children and their rights at risk. Most of the researchers treat all information as confidential, but confidentiality cannot be guaranteed. So, in order to ensure the confidentiality of actual research, some researchers may think that compromising the results to parents and caregivers is not something that could harm the children subjects. The issue of privacy, for example, encompasses the trade-offs between confidentiality and child safety and the need to maintain confidentiality in the dissemination of research findings ${ }^{20}$.

Conclusions: In order to safeguard and promote the rights, dignity and well-being of children in and through research, it is important to promote more thoughtful attention to the complex ethical problems that arise when conducting research that involves children. Before engaging in research on children it should first be clearly established that similar results could not possibly be obtained or derived from participants who are able to provide informed consent. Even if this is established, the vulnerability of children must always be considered and they should not take part in research unless there is potential for the participating child to benefit from the results of that research. Researchers should inform the children that they respect their right to withdraw from the research at any stage. Thus, it is the obligation of researchers to protect both the rights and welfare of research subjects. Hence, children should be given the chance to express their opinions, learn about themselves and their rights, while research activity must be regulated and the researchers must ensure that their rights of consent, confidentiality and unobstructed communication are protected at all times.

\section{References:}

1 Gerald P. Koocher and Patricia C. Keith-Spiegel, Ethical Approaches to Gathering Information from Children and Adolescents in International Settings: Guidelines and Resources, The Population Council Inc, USA, 2005, P. 3.

2 Rosie Flewitt, Conducting research with young children: some ethical considerations, Early Child Development and Care, Taylor Francis Group Ltd, 175(6), 2005, p 554.

3 Virginia Morrow, The Ethics of Social Research with Children and Families in Young Lives: Practical Experiences, Working Paper No. 53, Department of International Development, University of Oxford UK, Published by Young Lives, August 2009, p. 17.

4 MD Roth-Cline, J Gerson, P Bright, CS Lee \& RM Nelson, Ethical Considerations in Conducting Pediatric Research, In H Seyberth, A Rane, M Schwab, (Eds.) Pediatric Clinical Pharmacology, 1st Edition, Springer, 2011, p.1. 
5 Samantha Punch, Research With Children: The Same Or Different From Research With Adults?, Childhood, Department of Applied Social Science, University of Stirling UK, SAGE Publications London, vol. 9(3), 2002, pp.321-341.

6 World Health Association: Declaration of Helsinki, paras I.9, p. 11.

7 Shahanaz Chowdhury, Ethical Considerations in Research with Children, Bangladesh Journal of Bioethics, vol. 5(1) 2014, p. 37.

8 S J Neill, Research with children: A Critical Review of the Guidelines, J Child Health Care, vol. 9, 2005pp. 46-58.

9 Pia Christensen, "Working with Ethical Symmetry in Social Research with Children", Childhood, SAGE

Publications, London, vol. 9(4), 2002, p. 479.

10 G. P. Koocher \& P. C Keith-Spiegel, "Children Ethics and the Law: Professional Issues and Cases", Lincoln, Nebraska: University of Nebraska Press, 1990, p. 11.

11 MA Powell, RM Fitzgerald, N Taylor \& A Graham, "International literature review: ethical issues in Undertaking research with children and young people", the Child watch International Research Network, Southern Cross University, Centre for Children and Young People, Lismore NSW and University of Otago, Centre for Research on Children and Families, Dunedin, NZ, March 2012, pp. 1-51.

12 National Institutes of Health, Office of Human Subjects Research, The Belmont report: Ethical principles and guidelines for the protection of human subjects of research. <http://ohsr.od.nih.gov/guidelines/belmont.html> (accessed on 12 December 2014).

13 VA Miller, D Drotar, E Kodish, Children's Competence for Assent and Consent: A Review of Empirical Findings. Ethics Behav, vol. 14, 2004, p. 255.

14 S Joffe, CV Fernandez, RD Pentz, et al. Involving Children with Cancer in Decision-Making About Research Participation. J Pediatr. vol. 149, 2006, pp. 862-868.

15 H.Leonard \& J.D Glantz, Conducting Research with Children: Legal and Ethical Issues, SAGE Publications, 1995, p. 19.

16 Lovisa Skånfors, Ethics in Child Research:Children's Agency and Researchers' 'Ethical Radar' Childhoods Today, vol. 3 (1), 2009, pp. 1-5.

17 Guidance for developing ethical research projects involving children, Department of Children and Youth Affairs, Ireland, April 2012, p.1.Guidance for developing ethical research projects involving children.

http://www.dcya.gov.ie/documents/Publications/Ethics_Guidance.pdf. (access date:11/12/14)

18 Virginia Morrow and Martine Richards, The Ethics of Social Research with Children: An Overview", Children \& Society, vol. 10, 1996, pp. 90-105.

19 Katie Schenk, and Williamson Jan, Ethical Approaches to Gathering Information from Children and Adolescents in International Settings: Guidelines and Resources, Population Council. USA, 2005, pp.1-78.

20 CP MERG, Ethical Principles, Dilemmas and Risks in Collecting Data on Violence Against Children: A Review of Available Literature, Statistics and Monitoring Section/Division of Policy and Strategy, UNICEF, New York, 2012, p. 1-61.

Conflict of interest: Author declares no conflict of interest. 